\title{
sciendo
}

\section{Differences in Physical Performance According to the Competitive Level in Futsal Players}

\author{
by \\ Rubén Ayarra ${ }^{1}$ Fabio Yuzo Nakamura ${ }^{2,3}$, Aitor Iturricastillo ${ }^{1}$ Daniel Castillo ${ }^{1}$, \\ Javier Yanci ${ }^{1}$
}

The purpose of the present study was to describe performance in acceleration capacity, change of direction ability, vertical jump, horizontal jump, repeated sprint ability, and endurance (Yo-Yo Intermittent Recovery Test Level 1) in futsal players, and analyze the differences according to competitive categories or levels. The total sample $(n=40)$ was divided into three groups depending on the category in which the participants competed: Second Division $B(n=$ $15)$, Third Division $(n=12)$ and juniors $(n=13)$. All the tests were performed with participants' regular competition shoes and on the usual playing surface, in an indoor pavilion with a floating wood floor. The results of the study did not show significant differences in acceleration capacity $(5$ and $15 \mathrm{~m})$ or change of direction ability among the different categories. In contrast, significant differences were found among the categories with regard to horizontal jump and vertical jump capacity $(p<0.05)$; but not in all the variables analyzed. Performance in repeat sprint ability varied significantly among the different categories in $30 \mathrm{~m}(p<0.01)$ but not in $5 \mathrm{~m}(p>0.05)$. The distance covered in the YoYo Intermittent Recovery Test Level 1 by the Second Division B and the Third Division groups was greater than that covered by the junior group. In the light of these results repeated sprint ability and aerobic endurance could be two discriminating qualities of the competitive level among different futsal categories.

Key words: sprint, team sports, repeat sprint ability, physical fitness, age.

\section{Introduction}

Futsal is a team sport involving four field players and one goalkeeper per team, and the possibility of making an unlimited number of substitutions during the match (Cometti et al., 2001). It is played on a rectangular court measuring $40 \times 20 \mathrm{~m}$ and playing time is divided into 2 halves of $20 \mathrm{~min}$ with time stopping at every dead ball, so that total match time can be as much as 75-90 min (Alvarez et al., 2002). This variation in match time depends to a great extent on the possibilities offered by the rules: time-out, double penalties, cleaning the court or medical interventions (Barbero-Alvarez et al., 2008). Futsal is one of the most popular sports in Spain, both at the competitive (there are currently 100,000 federative licenses) and recreational level.

From the point of view of the demands of the game, it is a high-intensity intermittent sport which requires, in combination with a high degree of aerobic endurance, considerable strength and power from the players in order to carry out specific actions like accelerating, decelerating, tackling, jumping or changing direction (Gorostiaga et al., 2009). Although it is accepted that professional players cover distances of more than $4000 \mathrm{~m}$ in a match (Barbero-Alvarez et al., 2008; Dogramaci et al., 2011), given the regulations of the game, this distance can vary

\footnotetext{
1 - Physical Education and Sport Department, Faculty of Education and Sport, University of the Basque Country, UPV/EHU,

Vitoria-Gasteiz, Spain.

2 - The College of Healthcare Sciences, James Cook University, Queensland, Australia.

3 - Department of Medicine and Aging Sciences, "G. d'Annunzio" University of Chieti-Pescara, Pescara, Italy.
} 
considerably among players depending on the duration of their participation (De Oliveira et al., 2014). Thus, the distance covered per minute has been used as the most representative measure, and is equivalent to approximately $120 \mathrm{~m} \cdot \mathrm{min}^{-1}$ (Barbero-Alvarez et al., 2008; Dogramaci et al., 2011), which can be even greater when considering only the in-play time (De Oliveira et al., 2014). During a match, each player can perform approximately 26 sprints (i.e., $\geq 18.4$ $\left.\mathrm{km} \cdot \mathrm{h}^{-1}\right)$, sometimes involving short recovery periods (i.e. $15 \mathrm{~s}$ ) in between (Caetano et al., 2015). Cardiovascular work is higher than $85 \%$ of the maximum heart rate during more than $80 \%$ of actual playing time, underlying the need for futsal players to have maximal oxygen uptake $\left(\mathrm{VO}_{2 \max }\right)$ values $>60 \mathrm{ml} \cdot \mathrm{kg}^{-1} \cdot \mathrm{min}^{-1}$ (Alvarez et al., 2002; Barbero-Alvarez et al., 2008; Pedro et al., 2012).

A great deal of research has focused on differences in physical performance depending on the age or competitive level in different team sports (Abrantes et al., 2004; Gil et al., 2007; Ostrowski et al., 2012; Torres-Unda et al., 2013; Czuba et al., 2014). For example, differences in acceleration capacity over distances of up to $15 \mathrm{~m}$, vertical jump ability and agility have been investigated in junior, elite and sub-elite soccer players (Reilly et al., 2000). More recent investigations have emphasized the influence of age on improvements in the time recorded in repeated sprint tests in soccer players between 11 and 18 years (Mujika et al., 2009b), evidencing a plateau from 15 years of age on. However, these aspects have been studied to a lesser extent in futsal, in spite of its match locomotor intensity being greater than in soccer (Barbero-Alvarez et al., 2008). Some authors have suggested the possibility that speed achieved at $\mathrm{VO}_{2 \max }$, speed at the ventilatory threshold (VT), and even distance covered per match (indicators of "locomotor performance") could serve as variables to discriminate among the competitive levels of futsal players (Dogramaci et al., 2011; Pedro et al., 2012). Despite the fact that several studies carried out with futsal players have examined physiological demands (Barbero-Alvarez et al., 2004, 2009; Makaje et al., 2012; Pedro et al., 2012) or distance covered per match both in professional and non-professional players (Barbero-Alvarez et al., 2008; De Oliveira et al., 2014; Dogramaci et al., 2011), we have found only one study focusing on the performance differences in acceleration, vertical jump and cardiovascular tests in futsal players of different competitive levels (Naser and Ali, 2016). It could be interesting to perform more studies in this line in order to contrast the obtained results, as well as to analyze if there are any differences depending on the competition level in other capacities (i.e. change of direction ability) and in other performance tests. Knowledge of such differences can help fitness coaches in the selection of prospective players better suited to the higher levels of performance (Nakamura et al., 2016).

Therefore, the objectives of this study were, on the one hand, to describe performance in acceleration capacity, jumping, change of direction ability, repeated sprint ability and endurance in futsal players and, on the other, to analyze the differences in physical performance among futsal players of different competitive levels. The hypothesis of this study was that there would be significant differences in physical performance between futsal players of different competitive levels.

\section{Methods}

\section{Participants}

The investigated sample was composed of a total of 40 futsal players competing for the San Juan Sports Association (Pamplona, Spain) during the 2014/2015 season. All players trained three times a week and played one official match every weekend. The participants were divided into three groups according to the category in which they competed: Second Division B (G2B; $\mathrm{n}=15)$, Third Division (G3; $\mathrm{n}=12)$ and juniors (GJUN; $\mathrm{n}=$ 13). The inclusion criteria for the study were to have attended more than $85 \%$ of the training sessions during the two months prior to the tests and not to have suffered injuries which could prevent them from playing for more than 3 weeks in the three months prior to the study. All the players involved in the study volunteered to participate, were informed of the methodology to be used in the research and gave their written consent. The participation of the junior players (under 18) was authorized by their parents or legal guardians who signed their informed consent. All the procedures followed the guidelines indicated in the Declaration of Helsinki (2013). 


\section{Design}

This cross-sectional, descriptive and comparative study was carried out at the beginning of the second phase of the competitive period (January), after two weeks of the transitory period without competitions or training sessions. Before testing, all the participants carried out a week of re-adaptation to training (two sessions), when they practiced and performed the tests they would be submitted to. All the tests were performed with participants' regular competition shoes and on the usual playing surface, in an indoor pavilion with a floating wood floor. The players did not perform any intense physical activity for at least $48 \mathrm{~h}$ before the tests.

\section{Procedures}

The field tests were organized on nonconsecutive days with an interval of 7 days between the first and second session. Prior to each evaluation session, the participants performed a general standardized warm-up based on aerobic activation with continuous running for $3 \mathrm{~min}$, dynamic joint mobility for $5 \mathrm{~min}$, and three progressive accelerations of less than $30 \mathrm{~m}$. On the first day, they performed the acceleration test over 5 and $15 \mathrm{~m}$, vertical jump tests (VJ), horizontal jump tests $(\mathrm{HJ})$ and the repeated sprint ability test (RSA). On the second session the anthropometric variables, change of direction capacity (CODA) and aerobic endurance (Yo-Yo Intermittent Recovery Test level 1, YYIR1) were assessed. The recovery time between the different physical tests was $5 \mathrm{~min}$.

Anthropometric tests: anthropometric variables of body height $(\mathrm{m})$ and body mass $(\mathrm{kg})$ were measured for each participant with a height/weight scale (Atlántida, Sayol, Barcelona, Spain), with precision of $0.001 \mathrm{~m}$ and $0.01 \mathrm{~kg}$, respectively. The body mass index (BMI) was calculated using body weight and height $\left(\mathrm{kg} \cdot \mathrm{m}^{-2}\right)$.

Acceleration test over 5 and $15 \mathrm{~m}$ : straight line sprint time over 5 and $15 \mathrm{~m}$ was measured using infrared photoelectric cells (Microgate ${ }^{\circledR}$ Polifemo Radio Light, Bolzano, Italy). The starting position was standardized at a distance of $0.5 \mathrm{~m}$ behind the start line (Yanci et al., 2014), standing with one foot forward freely chosen by the player. The best of three trials was recorded with a recovery period of $2 \mathrm{~min}$ between repetitions.

Change of direction capacity test, CODA (505 agility test): in the CODA test the players had to run forward over a distance of $5 \mathrm{~m}$ to a line, pivot $180^{\circ}$ and return to the starting position (Yanci et al., 2014). A photocell (Microgate ${ }^{\circledR}$ Polifemo Radio Light, Bolzano, Italy) was placed on the start/finish line to record the time taken for the test. The players made an accelerated run from $10 \mathrm{~m}$ behind the start line where the time recording began (Figure 1). The participants carried out a total of 3 trials with 2 min recovery between each trial, and the best of the three results was chosen for further analysis.

Horizontal jump test (HJ): the distance for the countermovement horizontal jump was measured using a tape measure, following the protocol established by Ramírez-Campillo et al. (2015). The participants were instructed on how to use the arm swing in bilateral jump actions (HCMJAS), unilateral jump with the dominant (HCMJASD) and non-dominant leg (HCMJASND). The distance jumped in each of the trials was measured from the jumping line to the nearest part of contact on landing. The best result of three attempts was recorded for each type of the jump. The horizontal index of lateral asymmetry (HLA) was calculated using the following formula: [(D - ND) x $100 / \mathrm{ND}]$.

Vertical jump test (VJ): the participants carried out three bilateral vertical jump tests with countermovement and hands on the waist (VCMJ), three unilateral vertical jumps with the dominant leg (VCMJD) and three with the nondominant leg (VCMJND), choosing the best result of each jump for further analysis. The procedure of the jumps was according to the indications of Maulder and Cronin (2005). The height of the jump was determined using a contact platform (Optojump, Microgate ${ }^{\circledR}$, Bolzano, Italy). The vertical index of lateral asymmetry (VLA) was calculated using the formula: [(D - ND) $\times 100 /$ ND] (Impellizzeri et al., 2007).

Repeated sprint ability test (RSA): once the jump and acceleration tests were finished, each player had to perform 6 maximum sprints of $30 \mathrm{~m}$ with $25 \mathrm{~s}$ of active recovery between them. The time was measured for 5 and $30 \mathrm{~m}$ using three photoelectric cells (Microgate ${ }^{\circledR}$ Polifemo Radio Light, Bolzano, Italy). As indicators of performance, the sum of the times recorded to cover the 6 repetitions over $5 \mathrm{~m}$ (TT5m) and over $30 \mathrm{~m}$ (TT30m) (Pyne et al., 2008), the fatigue index associated with repeated sprint ability using the 
sprint decrement index (Sdec) determined using the equation: $\operatorname{Sdec}=($ RSAtotal/(RSA best $\times 6) \times$ 100 )-100 (Spencer et al., 2005) and the change in the fatigue index which relates the first and last sprint using the equation: Change $=(($ RSA latestRSA first )/(RSA first) ) x 100 were calculated (Pyne et al., 2008).

The Yo-Yo Intermittent Recovery Test level 1 (YYIR1): the YYIR1 is an intermittent test which is performed at progressive intensity until exhaustion and consists in shuttle runs $(2 \times 20 \mathrm{~m})$ with a progressive increase in speed, controlled by audio cues recorded on a CD and amplified by loudspeakers (Aiwa Twin Duct ${ }^{\circledR}$, Tokyo, Japan). The participants had $10 \mathrm{~s}$ of active rest interspersing the runs during which they had to walk $5 \mathrm{~m}$. The test finished when the subjects could no longer maintain the required speed or when they failed to reach the finishing line twice in succession. The total distance covered by each player was used as the criterion to estimate $\mathrm{VO}_{2 \max }$ (Bangsbo et al., 2008).

\section{Statistical analysis}

The mean and standard deviation (SD) were calculated for all the variables analyzed. All the variables showed a normal distribution according to the Shapiro-Wilk test. A one-way ANOVA was used to determine differences existing between the different categories with the corresponding Bonferroni post hoc test. A $t$ test for related samples was used to analyze the differences between the dominant (D) and nondominant leg (ND) both in the HJ and VJ. The practical differences were evaluated calculating the effect size using Cohen's $d$ (large: > 0.8; moderate: between 0.8 and 0.5 ; small: between 0.5 and 0.2; and trivial < 0.2) (Cohen, 1988). Data analysis was performed using the Statistical Package for Social Sciences (version 20.0 for Windows, SPSS ${ }^{\circledR}$, Chicago, IL, USA). Statistical significance was set at $\mathrm{p}<0.05$.

\section{Results}

Table 1 shows the results obtained with the anthropometric variables for the total sample and each of the groups (G2B, G3, GJUN). Differences $(p=0.02)$ could be detected among categories with regard to the BMI. More specifically, there were differences $(p=0.02, \mathrm{~d}=$ 1.18 , high) between G2B and GJUN groups, with the former presenting higher values for this variable. No differences in the variables of body mass and height were evident among the three categories.

The total sample presented mean values of $1.04 \pm 0.06 \mathrm{~s}$ and $2.37 \pm 0.22 \mathrm{~s}$ in the acceleration tests of 5 and $15 \mathrm{~m}$, respectively. With regard to the CODA test, the mean time recorded for the test by the total sample was $2.30 \pm 0.11 \mathrm{~s}$. The values obtained in the variables of acceleration and CODA did not show differences among the players from different competitive levels (Table 2). Although no differences between the categories were obtained in the acceleration capacity and CODA (Table 2), the GJUN group obtained better results than the G2B and G3 groups in the $15 \mathrm{~m}$ sprint $(\mathrm{d}=0.64$, moderate, $\mathrm{d}=$ 0.47 , small, respectively). However, considering CODA, the G2B and G3 groups obtained better results than the GJUN ( $\mathrm{d}=0.36$, small, $\mathrm{d}=0.80$, large, respectively).

Performance in the HJ showed differences between groups G3 and GJUN in the HCMJAS variable $(p=0.04, \mathrm{~d}=-1.55$, large) as shown in Table 3. Additionally, despite no significant differences between groups G3 and G2B, the former showed better results than G2B both in HCMJAS $(\mathrm{d}=0.98$, large $)$ and HCMJASD $(\mathrm{d}=$ 1.23, large), following the effect size analysis. However, in the VJ tests differences $(p<0.05)$ were obtained for the VCMJND variable between G2B and G3 in comparison to GJUN $(\mathrm{d}=-1.02, \mathrm{~d}=$ -1.08 , large). There were no significant differences in the rest of the VJ variables. With regard to the results obtained in bilateral asymmetry, the results revealed differences between G3 and GJUN ( $p=0.01, \mathrm{~d}=-1.73$, large) and a large effect size $(\mathrm{d}=1.08)$ between G2B and GJUN in VLA. However, the bilateral deficit for the HJ (HLA) was similar across all groups $(p>0.05, \mathrm{~d}<0.12$, trivial). The values for VLA were higher in all the groups compared to those for HLA (Table 3).

The results obtained by each group in the RSA and YYIR1 tests are shown in Table 4. Statistical analysis revealed no significant differences in any of the variables analyzed in RSA in $5 \mathrm{~m}$, but found some in $30 \mathrm{~m}$. On the one hand, the total time taken by each group to perform the 6 repetitions showed differences between the G2B and GJUN group ( $p=0.01, \mathrm{~d}=1.09$, large), with the G2B group recording lower time. On the other, the Sdec $30 \mathrm{~m}$ variable revealed differences between 
the G2B and G3 groups ( $p=0.01, \mathrm{~d}=1.09$, large). Furthermore, the Change $30 \mathrm{~m}$ also revealed differences $(p=0.00, \mathrm{~d}=1.82, \mathrm{~d}=-1.05)$ between the G2B and GJUN group compared to the G3 group. Regarding the values obtained in the YYIR1 test, there were no significant differences among the players of different competitive levels $(p>0.05)$. However, the Cohen's $d$ analysis revealed that the distance covered by the G2B and G3 groups was greater than that covered by the GJUN group $(\mathrm{d}=-0.71$, moderate, $\mathrm{d}=-0.94$, large, respectively). No differences $(p>0.05, \mathrm{~d}=-0.08)$ were found in the distance covered between the G2B and G3 groups.

Table 1

Means, standard deviations $( \pm S D)$ and Cohen's effect size (d) in the anthropometric variables of futsal players from the $2 n d$ Division $B, 3 r d$ Division and Junior Level.

\begin{tabular}{|c|c|c|c|c|c|c|c|}
\hline & TOTAL & G2B & G3 & GJUN & $\begin{array}{c}\mathrm{d} \\
\text { G2B- } \\
\text { G3 }\end{array}$ & $\begin{array}{c}\mathrm{d} \\
\text { G2B- } \\
\text { GJUN }\end{array}$ & $\begin{array}{c}\mathrm{d} \\
\text { G3-GJUN }\end{array}$ \\
\hline Age (yr) & $22.23 \pm 4.80$ & $27.60 \pm 3.38$ & $20.83 \pm 2.11$ & $17.99 \pm 0.91$ & $-2.04^{*}$ & $-2.86^{*}$ & $-1.34^{*}$ \\
\hline $\begin{array}{l}\text { Body } \\
\text { Heigth (m) }\end{array}$ & $1.76 \pm 0.07$ & $1.74 \pm 0.06$ & $1.78 \pm 0.08$ & $1.76 \pm 0.08$ & 0.75 & 0.42 & -0.26 \\
\hline $\begin{array}{l}\text { Body Mass } \\
(\mathrm{kg})\end{array}$ & $69.62 \pm 9.75$ & $72.07 \pm 7.95$ & $71.71 \pm 11.61$ & $65.05 \pm 8.65$ & 0.08 & -0.69 & -0.57 \\
\hline $\begin{array}{l}\mathrm{BMI} \\
\left(\mathrm{kg} \cdot \mathrm{m}^{-2}\right)\end{array}$ & $22.49 \pm 2.78$ & $23.78 \pm 2.10$ & $22.63 \pm 3.41$ & $20.96 \pm 2.11$ & -0.42 & $-1.18^{*}$ & -0.49 \\
\hline
\end{tabular}

G2B = Second Division group B; G3 = Third Division group; GJUN = Junior category group; $d=$ Cohen's effect size; BMI $=$ body mass index. ${ }^{*}$ Significant differences $(p<0.05)$ among the different groups.

\begin{tabular}{|c|c|c|c|c|c|c|}
\hline \multicolumn{7}{|c|}{$\begin{array}{c}\text { Table } 2 \\
\text { Means, standard deviations }( \pm S D) \text { and Cohen's effect size }(d) \text { in the variables } \\
\text { of acceleration and change of direction ability in futsal players from the Second Division B group, } \\
\text { Third Division and Junior Category. }\end{array}$} \\
\hline & $\mathrm{G} 2 \mathrm{~B}$ & G3 & GJUN & $\begin{array}{c}\mathrm{d} \\
\text { G2B-G3 }\end{array}$ & $\begin{array}{c}\mathrm{d} \\
\text { G2B-GJUN }\end{array}$ & $\begin{array}{c}\mathrm{d} \\
\text { G3-GJUN }\end{array}$ \\
\hline \multicolumn{7}{|l|}{ Sprint (s) } \\
\hline $\begin{array}{l}5 \mathrm{~m} \\
15 \mathrm{~m}\end{array}$ & $\begin{array}{l}1.04 \pm 0.06 \\
2.41 \pm 0.11\end{array}$ & $\begin{array}{l}1.04 \pm 0.06 \\
2.38 \pm 0.08\end{array}$ & $\begin{array}{l}1.04 \pm 0.06 \\
2.34 \pm 0.33\end{array}$ & $\begin{array}{l}-0.12 \\
-0.28\end{array}$ & $\begin{array}{l}-0.02 \\
-0.64\end{array}$ & $\begin{array}{c}0.11 \\
-0.47\end{array}$ \\
\hline \multicolumn{7}{|c|}{ CODA (s) } \\
\hline & $\begin{array}{r}d \text { Division } \\
\quad d=C_{0}\end{array}$ & $\begin{array}{l}\text { group; G3 } \\
\text { n's effect si }\end{array}$ & $\begin{array}{l}\text { Third Divisi } \\
C O D A=c\end{array}$ & $\begin{array}{l}\text { group; GJ } \\
\text { ge of dire }\end{array}$ & $\begin{array}{l}J=\text { Junior cat } \\
n \text { ability. }\end{array}$ & gory group; \\
\hline
\end{tabular}




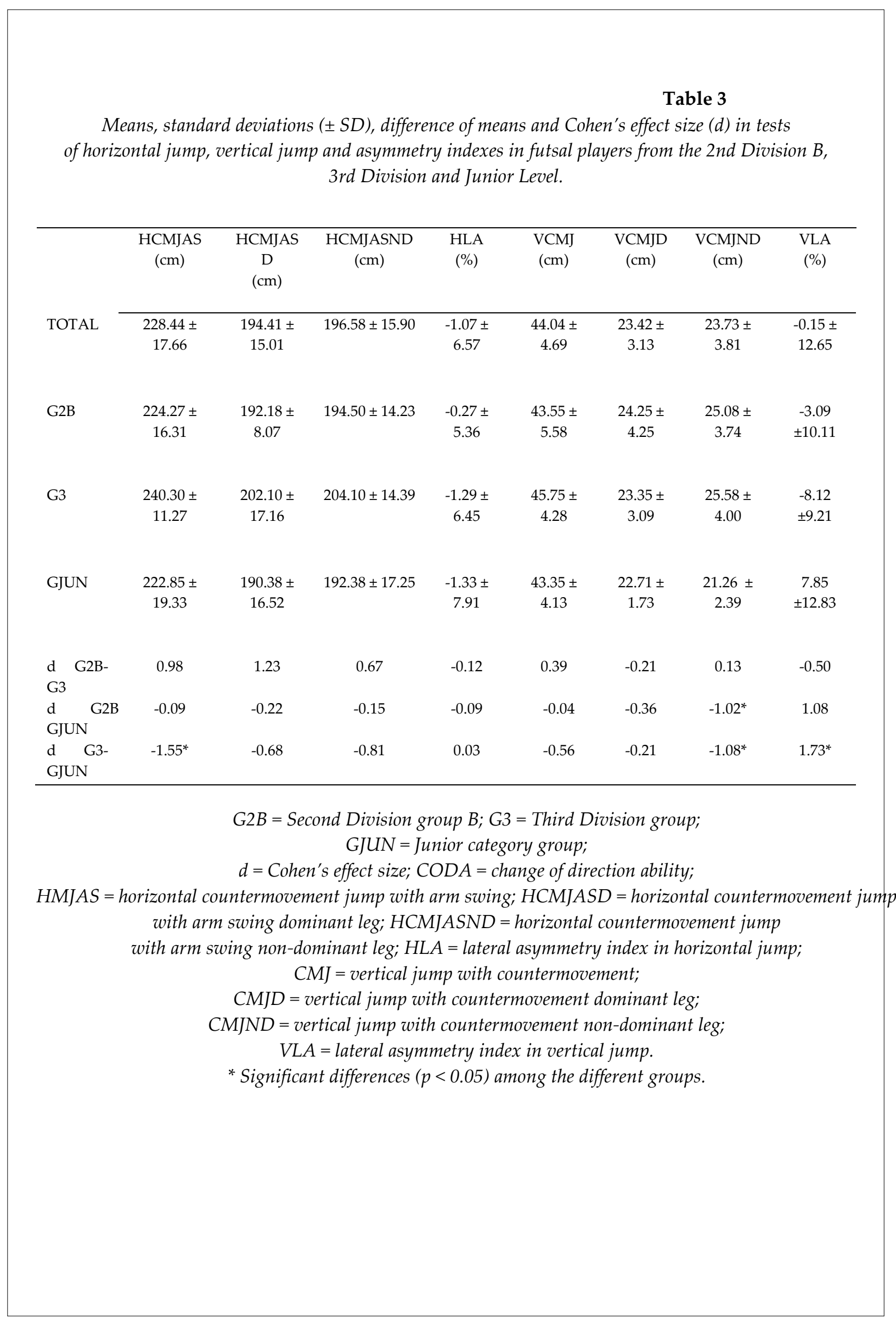


Table 4

Means, standard deviations ( $\pm S D$ ) and Cohen's effect size (d) in the RSA and Yo-Yo Intermittent Recovery test level 1 in futsal players from the Second Division group B, Third Division and Junior Category.

\begin{tabular}{|c|c|c|c|c|c|c|c|}
\hline & TOTAL & G2B & G3 & GJUN & $\begin{array}{l}\text { d G2B- } \\
\text { G3 }\end{array}$ & $\begin{array}{l}\text { d G2B- } \\
\text { GJUN }\end{array}$ & $\begin{array}{l}\text { d G3- } \\
\text { GJUN }\end{array}$ \\
\hline $\begin{array}{l}\text { RSA (s) } \\
\text { TT5 m }\end{array}$ & $6.56 \pm 0.44$ & $6.42 \pm 0.38$ & $6.56 \pm 0.29$ & $6.66 \pm 0.55$ & 0.38 & 0.66 & 0.36 \\
\hline TT30 m & $26.03 \pm 2.09$ & $\begin{array}{l}24.51 \pm \\
2.32\end{array}$ & $\begin{array}{l}26.24 \pm \\
1.31\end{array}$ & $27.05 \pm 1.81$ & 0.74 & $1.09^{* *}$ & 0.62 \\
\hline Sdec $5 \mathrm{~m}$ & $6.71 \pm 3.82$ & $6.75 \pm 4.39$ & $8.62 \pm 4.31$ & $5.22 \pm 2.27$ & 0.43 & 0.35 & -0.35 \\
\hline Sdec $30 \mathrm{~m}$ & $3.20 \pm 1.66$ & $2.43 \pm 1.35$ & $4.49 \pm 2.00$ & $2.81 \pm 0.97$ & $1.52^{* *}$ & 0.28 & -0.84 \\
\hline Change $5 \mathrm{~m}$ & $6.56 \pm 8.80$ & $4.18 \pm 9.66$ & $\begin{array}{l}10.50 \pm \\
10.00\end{array}$ & $4.99 \pm 6.71$ & 0.65 & 0.08 & -0.55 \\
\hline $\begin{array}{l}\text { Change } 30 \mathrm{~m} \\
\text { YYIR1 }\end{array}$ & $4.51 \pm 3.89$ & $1.96 \pm 3.34$ & $8.06 \pm 4.14$ & $3.74 \pm 1.58$ & $1.82^{* *}$ & 0.53 & $-1.05^{* *}$ \\
\hline Distance $(\mathrm{m})$ & $\begin{array}{l}1768.75 \pm \\
382.82\end{array}$ & $\begin{array}{l}1880 \pm \\
388.56\end{array}$ & $\begin{array}{l}1850 \pm \\
261.64\end{array}$ & $\begin{array}{l}1603.33 \pm \\
412.69\end{array}$ & -0.08 & -0.71 & -0.94 \\
\hline $\begin{array}{l}\text { VO2max } \\
\left(\mathrm{m} \cdot \mathrm{kg}^{-1} \cdot \mathrm{m}^{-1}\right)\end{array}$ & $51.26 \pm 3.22$ & $\begin{array}{l}52.19 \pm \\
3.26\end{array}$ & $\begin{array}{l}51.94 \pm \\
2.20\end{array}$ & $49.87 \pm 3.47$ & -0.08 & -0.71 & -0.94 \\
\hline
\end{tabular}

G2B = Second Division group B; G3 = Third Division group; GJUN = Junior category group; $d=$ Cohen's effect size; RSA = Repeat Sprint Ability; TT5 $m=$ total time over $5 m$ (sum of 6 repetitions); TT30 $m$ = total time over $30 \mathrm{~m}$ (sum of 6 repetitions); Sdec = Sprint decrement index; Change $=$ Fatigue index; YYIR1 $=$ Yo-Yo Intermittent Recovery Test level 1; $\mathrm{VO}_{2 \max }=$ maximum oxygen uptake.

** Significant differences $(p<0.01)$ among the different groups.

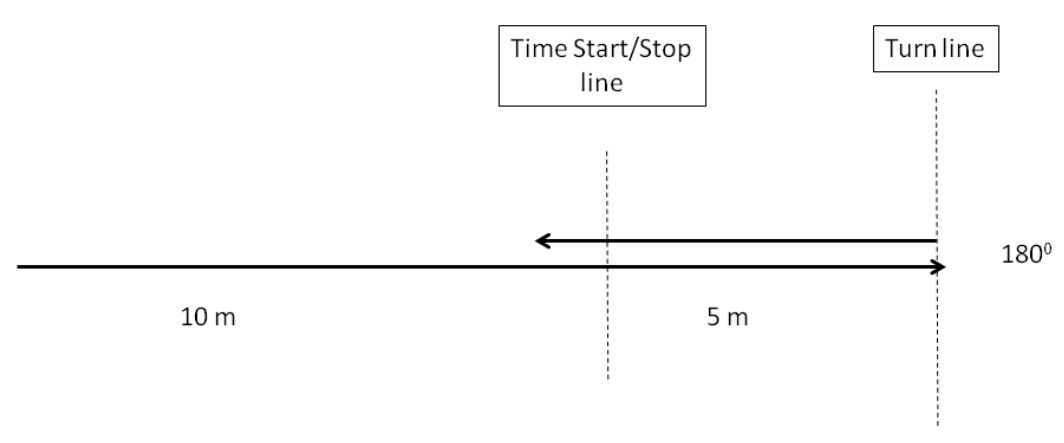

Figure 1

505 Agility test course. 


\section{Discussion}

The objectives of this study were to describe performance in selected physical fitness tests in futsal players, as well as to analyze the performance differences among players of different competitive levels. Futsal is a complex sport where performance will depend to a large extent, on adequate physical fitness among other aspects (Alvarez et al., 2002). However, only one study (Naser and Ali, 2016) has been found describing and analyzing physical performance in futsal players of different categories from the viewpoint of field tests.

In our study, according to the anthropometric variables, no significant differences were found between G2B and G3 groups, yet significant differences were evident between the group with of the highest competitive level (G2B) and the group of the lowest competitive level and younger age (GJUN). Group G2B presented a higher BMI than group GJUN. These results reflect those of Rivera (2006) in a study evaluating somatotype and proportionality in Mexican university soccer players with regard to professional soccer players, where it was found that the university players had lesser muscle and bone development, greater subcutaneous adiposity and lesser skeletal muscle development than the professional players. Similar results were obtained by Mujika et al. (2009a) among adult professional players and junior players in the Spanish League. The differences between the G2B and GJUN groups in our study could be due to lesser muscular development in the younger group. For this reason, we consider it could be interesting to take more precise and comprehensive measurements of body composition which would analyze the percentage of body fat, muscle mass and somatotype in futsal players.

Acceleration and CODA are fundamental aspects for performance in futsal (BarberoAlvarez et al., 2008; Castagna et al., 2009; Dogramaci et al., 2011; Tavassos et al., 2011). The results of our study did not show significant differences in performance among categories for the variables of acceleration and CODA. In contrast to our results, Cometti et al. (2001) stated that French professional soccer players scored better results than amateur soccer players in their times for a $10 \mathrm{~m}$ sprint. In the same line, Naser and Ali (2016) also observed differences in sprint performance between players of different categories. However, the results obtained by Mujika et al. (2009a) coincide with ours as they did not find significant differences in the $15 \mathrm{~m}$ sprint between adult and junior players. With regard to CODA, Mujika et al. (2009a), in agreement with our study, found no significant differences between Spanish first division soccer players and junior players in the $15 \mathrm{~m}$ agility test. The characteristics of each test with regard to distances, types of changes of direction and duration as well as characteristics of the players could condition the results obtained. For this reason, it may be necessary to carry out further research on this aspect to determine which acceleration and CODA tests are more specific to futsal. More research is needed to analyze whether the acceleration capacity and CODA discriminate according to the competitive level of futsal players.

With respect to jumping ability, significant differences found in the $\mathrm{HJ}$ variable between the G3 and GJUN groups are interesting in the sense that the G3 group achieved the best values in HCMJAS and HCMJASD, outperforming the group from the highest competitive level (G2B). Only few studies have focused on assessing HJ capacity (RamirezCampillo et al., 2015; Soares-Caldeira et al., 2014; Yanci et al., 2014), in spite of the importance of horizontal strength in sports like soccer and futsal. In fact, Maulder and Cronin (2005) point to the greater specificity of $\mathrm{HJ}$ tests in comparison with VJ tests. In this line, Santiago et al. (2015) observed differences in $\mathrm{HJ}$ between junior and under- 15 category players $(\mathrm{p}<0.01, \mathrm{~d}>0.8$, high). The fact that the G2B group did not score better results than the rest of the groups in our study indicates that there may be other factors which are more important in futsal like for example the individual technique of the player, team tactics, experience or psychological aspects among others. In addition, the volume of plyometrics in general and horizontal jumps in specific, in professional futsal teams are very low (unpublished results).

With regard to performance in VJ, significant differences were obtained in the VCMJND between the G2B and G3 groups in comparison to the GJUN group, but not in the VCMJ or the VCMJD. These results coincide with 
those obtained by Castagna and Castellini (2013) as they found no significant differences among Italian soccer players of different ages and categories, or with those of Mujika et al. (2009a), who also did not find difference in VJ between adult and junior soccer players. Similarly, Santiago et al. (2015) observed that VJ capacity was similar between junior and under-15 category players. In futsal, a previous study has shown that VJ was not different between under-20 and senior ( $\approx 28$ years) professional players (Nakamura et al., 2016). Therefore, despite VJ having been described as a valid test for talent identification and differentiating between competitive levels in team sports, our results suggest that perhaps VJ is not an adequate tool for discriminating between performance levels among different categories in futsal.

In our study, a comparison of the competitive level indicated a range of variation in the $30 \mathrm{~m}$ RSA test performance from higher to lower competitive sports categories in the TT30 m, with significant differences between G2B and GJUN groups. However, none of the variables analyzed in the $5 \mathrm{~m}$ RSA test revealed significant differences among categories. The fatigue indexes associated with RSA also showed significant differences between categories in the Sdec $30 \mathrm{~m}$ for groups G2B and G3, and in the Change $30 \mathrm{~m}$ between groups G2B-G3 and G3-GJUN. Importantly, this is the first study to compare RSA performance among different competitive levels and age groups in futsal. Our results coincide with findings from other studies carried out with soccer players of different ages (Abrantes et al., 2004; Mendez-Villanueva et al., 2011; Mujika et al., 2009b) and competitive levels (Alvarez et al., 2002; Rampinini et al., 2009). For example, Abrantes et al. (2004) found differences among age groups (under-12, under-14 and under-16), and also observed significant differences among groups of different training and competitive levels (1st and 2nd National Categories and 1st Regional Division). Therefore, it could be concluded that players of a higher competitive level have better performance in RSA than players of a lower level. This aspect underlines that repeated sprint ability can also be a specific and discriminating quality in futsal players. For this reason, futsal team coaches should consider improving their players' RSA performance. However, it should be noticed that
RSA is resilient to specific repeated sprint training in futsal players (Soares-Caldeira et al., 2014), and effective methods to improve it should be investigated.

Bearing in mind that heart rate values recorded in matches are higher than $85 \%$ of the maximum heart rate for more than $80 \%$ of actual playing time (Barbero-Alvarez et al., 2008), aerobic capacity of players is a factor which should be taken into account by coaches and physical trainers in order to optimize performance levels in their players. The distance covered in the YYIR1 by our futsal players also reflected the order of a higher to lower category, with the players from the G2B group attaining the best results, although the differences were not significant. Nevertheless, the effect sizes ranged from moderate to large $(\mathrm{d}>-0.71$ and -0.94$)$ between G2B-G3 and G3-GJUN. Previous studies have shown that top level professional players were capable of covering up to $10 \%$ more distance in the YYIR1 than professional players at a medium level (Mohr et al., 2003). Similarly, Mujika et al. (2009a) found significant differences among junior players and professional players in the Spanish soccer league in performance of the YYIR1 in favour of the players at the higher competitive level, showing that the ability to carry out high-intensity intermittent exercise can be a discriminating value for the competitive level in soccer. In futsal players, it has been shown that YYIR1 was better in professional seniors $(\approx 1500$ $\mathrm{m})$ than in younger under-20 players $(\approx 1250 \mathrm{~m})$ (Nakamura et al., 2016). In the light of our results, we find aerobic endurance to be an important quality for the competitive level in futsal. Considering our results, it seems important to improve cardiovascular capacity of futsal players.

In conclusion, the players of a higher competitive level did not record a better performance in the acceleration tests (5 and $15 \mathrm{~m}$ ), change of direction ability, bilateral vertical jump and horizontal jump in comparison with players of a lower competitive level or a younger age. Given the importance shown by other authors of these qualities in intermittent sports, it seems necessary for coaches and physical trainers to study the possibility of introducing specific training contents to address these aspects. 


\section{References}

Abrantes C, Maçãs V, Sampaio J. Variation in football player's sprint test performance across different ages and levels of competition. J Sports Sci Med, 2004; 3: 44-49

Álvarez J, Giménez L, Corona P, Manonelles P. Cardiovascular and metabolic necessities of indoor football: analysis of the competition. Apunts. Phys Educ Sports, 2002; 67: 45-53

Bangsbo J, Iaia F, Krustrup P. The Yo-Yo intermittent recovery test - A useful tool for evaluation of physical performance in intermittent sports. Sports Med, 2008; 38: 37-51

Barbero-Alvarez JC, Granda J, Soto, V. A Heart rate analysis during competiton in professional futsal players. Apunts. Phys Educ Sports, 2004; 77: 71-78

Barbero-Alvarez JC, Soto V, Barbero-Alvarez V, Granda J. Match analysis and heart rate of futsal players during competition. J Sports Sci, 2008; 26: 63-73

Barbero-Alvarez JC, D'Ottavio S, Granda J, Castagna C. Aerobic fitness in futsal players of different competitive level. J Strength Cond Res, 2009; 23: 2163-2166

Caetano F, Bueno M, Marche A, Nakamura F, Cunha S, Moura F. Characterization of the sprints and repeated-sprint sequences performed by professional futsal players during official matches according to playing position. J Appl Biomech, 2015; 31(6): 423-429

Castagna C, D'Ottavio S, Granda J, Barbero-Alvarez JC. Match demands of professional Futsal: a case study. J Sci Med Sport, 2009; 12: 490-494

Castagna C, Castellini E. Vertical jump performance in Italian male and female national team soccer players. J Strength Cond Res, 2013; 27: 1156-1161

Cohen J. Statistical power analysis for the behavioral sciences. Hillsdale, NY: LEA; 1988

Cometti G, Maffiuletti NA, Pousson M, Chatarrd JC, Maffulli N. Isokinetic strength and anaerobic power of elite, subelite and amateur French soccer players. Int J Sport Med, 2001; 22: 45-51

Czuba M, Maszczyk A, Gerasimuk D, Roczniok R, Fidos-Czuba O, Zając A, Gołaś A, Mostowik A, Langfort J. The effects of hypobaric hypoxia on erythropoiesis, maximal oxygen uptake and energy cost of exercise under normoxia in elite biathletes. J Sports Sci Medic, 2014; 13(4): 912-920

De Oliveira Bueno MJ, Caetano FG, Pereira,TJ, De Souza NM, Moreira GD, Nakamura FY, Cunha SA, Moura FA. Analysis of the distance covered by Brazilian professional futsal players during official matches. Sports Biomech, 2014; 13(3): 230-40

Dogramaci SN, Watsford ML, Murphy AJ. Time-motion analysis of international and national level futsal. J Strength Cond Res, 2011; 25: 646-651

Gil S, Ruiz F, Irazusta A, Gil J, Irazusta J. Selection of young soccer players in terms of anthropometric and physiological factors. J Sports Med Phys Fit, 2007; 47: 25-32

Gorostiaga EM, Llodio I, Ibáñez J, Granados C, Navarro I, Ruesta M, Bonnabau H, Izquierdo M. Differences in physical fitness among indoor and outdoor elite male soccer players. Eur J Appl Physiol 2009; 106: 483-91

Impellizzeri FM, Rampinini E, Maffiuletti N, Marcora SM. A vertical jump force test for assessing bilateral strength asymmetry in athletes. Med Sci Sports Exerc, 2007; 39: 2044-50

Makaje N, Ruangthai R, Arkarapanthu A, Yoopat P. Physiological demands and activity profiles during futsal match play according to competitive level. J Sports Med, Phys Fit 2012; 52: 366-374

Maulder P, Cronin J. Horizontal and vertical jump assessment: reliability, symmetry, discriminative and predictive ability. Phys Ther Sport, 2005; 6: 74-82

Mendez-Villanueva A, Buchheit M, Kuitunen S, Douglas A, Peltola E, Bourdon P. Age-related differences in acceleration, maximum running speed, and repeated-sprint performance in young soccer players. $J$ Sports Sci, 2011; 29: 477-484

Mohr M, Krustrup P, Bangsbo J. Match performance of high-standard soccer players with special reference to development of fatigue. J Sports Sci, 2003; 21: 519-528 
Mujika I, Santisteban J, Impellizzeri FM, Castagna C. Fitness determinants of success in men's and women's football. J Sports Sci, 2009a; 27: 107-114

Mujika I, Spencer M, Santisteban J, Goiriena JJ, Bishop D. Age-related differences in repeated-sprint ability in highly trained youth football players. J Sports Sci, 2009b; 27: 1581-1590

Nakamura FY, Pereira LA, Cal Abad CC, Kobal R, Kitamura K, Roschel H, Rabelo F, Souza-Junior WA, Loturco I. Differences in physical performance between U-20 and senior top-level Brazilian futsal players. J Sports Med Phys Fit, 2016; 56(11): 1289-1297

Naser N, Ali A. A descriptive-comparative study of performance characteristics in futsal players of different levels. J Sports Sci, 2016; 34(18): 1707-1715

Ostrowski A, Strzała M, Stanula A, Juszkiewicz M, Pilch W, Maszczyk A. The Role of Training in the Development of Adaptive Mechanisms in Freedivers. J Hum Kinet, 2012; 32: 197-210

Pedro RE, Milanez VF, Boullosa D, Nakamura FY. Running speeds at ventilatory threshold and maximal oxygen consumption discriminate futsal competitive level. J Strength Cond Res, 2012; 27: 514-518

Pyne D, Saunders P, Montgomery P, Hewitt A, Sheehan K. Relationships between repeates sprint testing, speed, and endurance. J Strength Cond Res, 2008; 22: 1633-1637

Ramírez-Campillo R, Gallardo F, Henriquez-Olguín C, Meylan C, Martínez C, Álvarez C, Caniuqueo A, Cadore E, Izquierdo M. Effect of vertical, horizontal and combined plyometric training on explosive, balance and endurance performance of young soccer players. J Strength Cond Res, 2015; 29(7): 17841795

Rampinini E, Sassi A, Morelli A, Mazzoni S, Fanchini M, Coutts AJ. Repeated-sprint ability in professional and amateur soccer players. Appl Physiol Nutr Metab, 2009; 34: 1048-1054

Reilly T, Williams AM, Nevill A, Franks A. A multidisciplinary approach to talent identification in soccer. J Sports Sci, 2000; 18: 695-702

Rivera J. Evaluation of the somatotype and proportionality of university soccer players with respect to professional soccer players. Int J Med Sci Phys Act Sport, 2006; 6(21): 16-28

Santiago A, Granados C, Quintela K, Yanci J. Differences in the acceleration, change of direction and jumping capacity between different ages soccer players. Cult Sci Sport, 2015; 10(29): 135-143

Soares-Caldeira LF, de Souza EA, de Freitas VH, de Moraes SM, Leicht AS, Nakamura FY. Effects of additional repeated sprint training during preseason on performance, heart rate variability, and stress symptoms in futsal players: a randomized controlled trial. J Strength Cond Res, 2014; 28: 28152826

Spencer M, Bishop D, Dawson B, Goodman C. Physiological and metabolic responses of repeated-sprint activities specific to field-based team sports. Sports Med, 2005; 35: 1025-1044

Torres-Unda J, Zarrazquin I, Gil J, Ruiz F, Irazusta A, Kortajarena M, Seco J, Irazusta J. Anthropometric, physiological and maturational characteristics in selected elite and non-elite male adolescent basketball players. J Sports Sci, 2013; 31: 196-203

Travassos B, Araújo D, Vilar L, McGarry T. Interpersonal coordination and ball dynamics in futsal (indoor football). Hum Movement Sci, 2011; 30(6): 1245-1259

Yanci J, Arcos AL, Mendiguchia J, Brughelli M. Relationships between sprinting, agility, one and two-leg vertical and horizontal. Kinesiol, 2014; 46: 194-201

\section{Corresponding author:}

\section{Javier Yanci, PhD}

University of the Basque Country (UPV/EHU), Faculty of Education and Sport,

Lasarte 71, 01007 Vitoria-Gasteiz, Spain.

Tel. 0034945013529

E-mail: javier.yanci@ehu.es 